2. Kassebaum NJ, Jasrasaria R, Naghavi M, et al. A systematic analysis of global anemia burden from 1990 to 2010. Blood 2014; 123(5): 615-624.

3. Muñoz M, Gómez-Ramirez S, Kozek-Langeneker S. Pre-operative haematological assessment in patients scheduled for major surgery. Anaesthesia 2016; 71(Suppl 1): 19-28.

4. Fowler AJ, Ahmad T, Phull MK, et al. Metaanalysis of the association between preoperative anaemia and mortality after surgery. Br J Surg 2015: 102(11): 1314-1324.

5. Richards T, Clevenger B, Keidan J, et al. PREVENTT: preoperative intravenous iron to treat anaemia in major surgery: study protocol for randomised control trial. Trials 2015: 16: 254

DOI: https://doi.org/10.3399/bjgp17X690137

\section{Do primary care chaplains need training in mental health \\ issues?}

I read with interest $\mathrm{Dr}$ Macdonald's article, which showed that talking therapy by chaplains resulted in an equivalent improvement in patient wellbeing as antidepressants.

Leavey et $a l^{2}$ in an interview study concluded that clergy tend to explain mental health problems in terms of social factors with spiritual influences and for them the meaning of mental distress assumes more social and moral significance. Pennybaker et $a^{3}$ have suggested there is a need to provide chaplains with training in psychiatric illness and to more clearly define their role in mental health care.

Dr Macdonald suggests primary care chaplaincy could be considered as an alternative to cognitive behavioural therapy but before adopting this strategy more widely it would be useful to obtain the views of chaplains on what talking therapy means to them and what training they would need to provide it.

\section{lan J Hamilton,}

Researcher, Institute of Health and Wellbeing, University of Glasgow. E-mail: ijdhamiltondadoctors.org.uk

\section{REFERENCES}

1. Macdonald G. Primary care chaplaincy: a valid talking therapy? Br J Gen Pract 2017; https://doi. org/10.3399/bjgp17X689221.

2. Leavey G. Loewenthal K, King M. Locating the social origins of mental Illness: the explanatory models of mental illness among clergy from different ethnic and faith backgrounds. J Relig Health 2016; 55(5): 1607-1622

3. Pennybaker S, Hemming P. Roy D, et al. Risks, benefits and recommendations for pastoral care on inpatient psychiatric units: a systematic review. J Psych Pract 2016; 22(5): 363-381.

DOI: https://doi.org/10.3399/bjgp17X690149

\section{Incorporating cancer risk information into general practice: a qualitative study using focus groups with health professionals}

Usher-Smith et al report a useful study in the potential utility of cancer risk assessment tools in general practice. Readers may be interested to know that the www.qcancer.org tool, which calculates risk of a current but as yet undiagnosed cancer, was integrated into EMISWeb in 2016; the most popular GP computer system, used by over $55 \%$ of all GPs in the UK.

Also there is a new tool that predicts 10 -year risk of different types of cancer. taking account of family history and lifestyle as well as other risk factors that are readily available. ${ }^{2}$ There is an online calculator for women (http://qcancer.org/10yr/female/) and one for men (http://qcancer.org/10yr/male/).

\section{Julia Hippisley-Cox,}

Professor of Clinical Epidemiology and General Practice, University of Nottingham, and ClinRisk Ltd.

E-mail: julia.hippisley-coxßnottingham.ac.uk

\section{Competing interests}

Julia Hippisley-Cox is Professor of Clinical Epidemiology at the University of Nottingham and co-director of QResearch ${ }^{\circledast}$, a not-for-profit organisation that is a joint partnership between the University of Nottingham and Egton Medical Information Systems (leading commercial supplier of IT for $60 \%$ of general practices in the UK). Julia Hippisley-Cox is also a paid director of ClinRisk Ltd, which produces open- and closed-source software to ensure the reliable and updatable implementation of clinical risk algorithms within clinical computer systems to help improve patient care.

\section{REFERENCES}

1. Usher-Smith JA, Silarova B, Ward A, et al. Incorporating cancer risk information into general practice: a qualitative study using focus groups with health professionals. Br J Gen Pract 2017; DOI: https://doi.org/10.3399/bjgp17X689401.

2. Hippisley-Cox J, Coupland C. Development and validation of risk prediction algorithms to estimate future risk of common cancers in men and women: prospective cohort study. BMJ Open 2015; 5(3): e007825. DOI: 10.1136/bmjopen-2015-007825

DOI: https://doi.org/10.3399/bjgp17X690161

\section{The wrong paradigm may be driving drug glucose control in the face of the evidence}

Boussageon et al are the latest to highlight the apparent contradiction in our current thinking.

On the one hand, the epidemiological evidence shows a strong link between chronic hyperglycaemia (HbA1c) and adverse patient-important outcomes. On the other hand, the evidence from randomised controlled trial shows that lowering $\mathrm{HbA} 1 \mathrm{c}$ by drug treatment is ineffective or harmful to patient outcomes.

This contradiction is because we are using the wrong paradigm.

The current paradigm is that $\mathrm{HbA} 1 \mathrm{c}$ has a causal relationship with adverse outcomes and that lowering $\mathrm{HbA} 1 \mathrm{c}$ by any means must improve patient-important outcomes.

The alternative paradigm is that chronic hyperglycaemia is partly causal, but is only a late and easily measurable part of a more fundamental problem.

Our culturally 'normal' diet, based on carbohydrate, is biologically different from the diet the human species evolved to thrive on. A large proportion of people cannot tolerate a carbohydrate-based diet over years, even 'healthy whole grains'. Eating starch is eating glucose, which requires a corresponding insulin response. An insulin response with every snack and meal for years can, in genetically vulnerable people, cause insulin resistance with variable expression among people and among different body tissues. The Hyperinsulinaemia and Insulin Resistance (HAIR) is the underlying problem driving disorders of glucose and lipid metabolism, characterised by pathological fat deposition as central and visceral obesity, metabolic syndrome, and, when 
the body's compensatory mechanisms fail, type 2 diabetes mellitus (T2DM). The whole problem is the cause of the patient-important outcomes, not just the hyperglycaemia.

It is now easy to see: if drugs lower HbA1c by raising insulin and worsening HAIR, this can be ineffective or harmful to patient outcomes.

The standard treatment of T2DM, endorsed by the drug industry, is to base every meal on carbohydrate, which may worsen the underlying insulin response and HAIR, rapidly followed by multiple chronic drug prescriptions, which may be ineffective or harmful even while temporarily improving $\mathrm{HbA} 1 \mathrm{c}$.

A low carbohydrate, high healthy fat 'real food' diet can reverse the underlying dietary cause, offload the pressure on glucose and lipid metabolism, and allow the HAIR and T2DM to gradually recover.

Craig A McArthur,

GP Partner, NHS Highland.

E-mail: craig.mcarthuranhs.net

\section{REFERENCE}

1. Boussageon R, Pouchain D, Renard V. Prevention of complications in type 2 diabetes: is drug glucose control evidence based? Br J Gen Pract 2017; DOI: https://doi.org/10.3399/bjgp17X689317.

\section{Medically unexplained symptoms}

Hard evidence regarding diagnosis, care, and management of this area of practice is, unsurprisingly, hard to come by. It is disappointing that the article by Chew-Graham et al does not specifically mention the importance of personal continuity of care in these cases, and the desirable development of trust of a patient with a clinician. ${ }^{1}$ Fragmented care at best makes management of patients with these conditions difficult. Without trust, satisfactory explanation, and understanding, a positive impact is much less likely. At its worst, fragmented care can act as a reinforcement rather than a relief of symptoms.

Only with this recognition, and appropriate dedicated review opportunities within the GP appointment system lperhaps into which ONLY the GP is authorised to book), can desirable continuity be achieved (continuity was given prominence with several articles in BMJ 2017; 356).

Vernon H Needham,

Retired GP, Provost, Wessex Faculty RCGP.

E-mail: vernonneedhamanhs.net

\section{REFERENCE}

1. Chew-Graham CA, Heyland S, Kingstone T, et al. Medically unexplained symptoms: continuing challenges for primary care. Br J Gen Pract 2017; DOI: https://doi.org/10.3399/bjgp17X689473.

DOI: https://doi.org/10.3399/bjgp17X690185

\section{Giving patients choice of appointment length}

I appreciated Natasha Elmore's thoughtful and considered responses to correspondence linked to her recent publication. ${ }^{1-3}$

We previously carried out work on giving patients the choice of appointment length, 4 and found (contrary to GPs' expectation) that patients were accurate at estimating appointment length required. Having chosen a specific appointment length, patients also gave careful thought as to how they may manage their own consultation, based on consult duration preference.

\section{Rod Sampson,}

GP, Cairn Medical Practice, Inverness. E-mail: rod.sampsonanhs.net

\section{REFERENCES}

1. Elmore N, Burt J, Abel G, et al. Sharing control of appointment length with patients in general practice: a qualitative study. Br J Gen Pract 2016; DOI: https://doi.org/10.3399/bjgp16X687733.

2. Elmore N, Burt J. Consultation length: author response to Dr Brian Goss. [Letter]. Br J Gen Pract 2017; DOI: https://doi.org/10.3399/bjgp17X689521.

3. Elmore N, Burt J. Consultation length: author response to Dr Brigid Joughin. [Letter]. Br J Gen Pract 2017; DOI: https://doi.org/10.3399/ bjgp17X689533.

4. Sampson R, O'Rourke J, Hendry R, et al. Sharing control of appointment length with patients in general practice: a qualitative study. $\mathrm{Br} \mathrm{J}$ Gen Pract 2013; DOI: https://doi.org/10.3399/ bjgp13X664234

DOl: https://doi.org/10.3399/bjgp17X690197

\section{Bad medicine: red drugs}

I am grateful to Des Spence for highlighting the issue of drug diversion in his recent piece. 'The redirection of legally acquired medications into illicit channels undoubtedly perpetuates drug culture in society and causes significant harm to the individual: emotional, physical, financial, and otherwise.

However, I feel he is misguided in suggesting that this issue is driven by the widely held idea that pain is what the patient says it is', or more specifically by prescription practices based on this tenet. Though he rejects it as unscientific and false', to me this simple statement neatly conveys the notion that pain is a nebulous phenomenon, occurring without the tangible anatomical or biochemical substrate that might allow it to be measured objectively.

The corollary of Spence's view is then surely that pain is not always what the patient says it is; but it is hard to see how this stance would be useful, or indeed workable, in clinical practice. It implies a need for doctors to distinguish the genuine from the fraudulent. Not only is this impossible, given pain is subjective and unquantifiable, but it also welcomes prejudice. How might we identify would-be drug diverters? Do they really look or behave in the stereotyped manner that Spence portrays? I would argue that mispronouncing a drug's name has poor positive predictive value in this respect.

Allowing doctors to become the arbiters of their patients' pain is not a credible solution to the quiet epidemic of drug diversion. Under-treatment of valid pain will beget unnecessary suffering and it is easy to conceive that sufficiently determined patients will contrive increasingly elaborate, disingenuous methods to acquire the prescriptions they seek.

\section{Matthew J Sliney,}

Clinical Medical Student, University of Oxford. E-mail: matthew.slineylamagd.ox.ac.uk

\section{REFERENCE}

1. Spence D. Bad medicine: red drugs. Br J Gen Pract 2017; DOI: https://doi.org/10.3399/ bjgp17X689185. 